\title{
AUDIOS Y VIDEOS CORTOS AUTÉNTICOS EN LA PERCEPCIÓN DE PROCESOS FONOLÓGICOS: ACTITUDES DE ESTUDIANTES ARGENTINOS UNIVERSITARIOS DE INGLÉS CON NIVEL INTERMEDIO
}

\author{
Bettiana Blázquez \\ Universidad Nacional del Comahue- UNCO (Argentina) \\ bettianablazquez@hotmail.com. \\ María de los Ángeles Peña Hita \\ Universidad de Jaén- UJA (España) \\ mapena@ujaen.es.
}

\begin{abstract}
Resumen. El presente estudio se enmarca dentro de la tesis doctoral denominada "Efectos de audios y videos cortos auténticos: reconocimiento de procesos fonológicos y actitudes de estudiantes argentinos universitarios de inglés con nivel intermedio". Este trabajo en particular se centra en las actitudes de los estudiantes hacia audios y videos cortos auténticos en el reconocimiento de procesos fonológicos del inglés hablado. Los sujetos de estudio son estudiantes de la asignatura Fonética y Fonología Inglesa I de las carreras de Profesor y Traductor Público de Inglés en la Facultad de Lenguas (FADEL) de la Universidad Nacional del Comahue (UNCo), Argentina. Se emplea un diseño cuasi-experimental basado en dos grupos: el audiovisual y el audio. El primero $(n=32)$ es expuesto a segmentos de video auténticos para desarrollar la percepción de procesos fonológicos, mientras que el segundo $(n=34)$ es instruido mediante este mismo material, pero sin soporte visual. Los segmentos utilizados son: video musical, preestreno, avisos comerciales, documental, cortometraje y escena de película. Las actitudes del estudiantado se examinan antes y después de la intervención. Para tal fin, se administran un cuestionario informativo y un cuestionario de valoración. Del análisis de los datos se deduce que los estudiantes manifiestan una actitud positiva hacia ambos recursos, siendo más positiva hacia el recurso audiovisual antes y después de la intervención. Se espera seguir explorando los efectos de los distintos tipos de videos breves en la percepción de procesos fonológicos y en otros aspectos de la pronunciación.
\end{abstract}

Palabras clave: videos cortos auténticos, audios, actitudes, procesos fonológicos, enseñanza.

\section{AUTHENTIC AUDIO AND VIDEO SEGMENTS IN THE PERCEPTION OF PHONOLOGICAL PROCESSES: ATTITUDES OF ARGENTINEAN UNIVERSITY STUDENTS WITH AN INTERMEDIATE LEVEL OF ENGLISH}

\begin{abstract}
The present study is part of the doctoral thesis entitled "Effects of authentic audio and video segments: recognition of phonological processes and attitudes of Argentinean university students with an intermediate level of English". Particularly, this study focuses on the students' attitudes towards the audio and video authentic segments in the identification of phonological processes in spoken English. The participants of this research study are students of English Phonetics \& Phonology I, one of the subjects of the Teacher Training and Translation courses at the Faculty of Language (FADEL), Comahue University (UNCo), Argentina. Two intact groups are used as a basis for a quasi-experiment, named audiovisual and audio groups respectively. The former $(n=32)$ is instructed by means of video segments to develop the perception of phonological processes, whereas the latter one $(n=34)$ is exposed to the same material without its visual component. The different video segments used are a music clip, a preview, TV commercials, a documentary, a short and a scene. The students' attitudes are examined before and after the treatment. The gathering techniques are a background questionnaire and an assessment questionnaire. The results reveal
\end{abstract}


that the learners show a positive attitude towards both audio and video segments. Yet, a more positive opinion on short authentic videos is observed before and after the intervention. It is expected to explore the effects of different types of short videos on the perception of phonological processes and other aspects of pronunciation.

Keywords: authentic video segments, audio material, phonological processes, attitudes, teaching.

\title{
ÁUDIOS E VÍDEOS CURTOS AUTÊNTICOS NA PERCEPÇAO DE PROCESSOS FONOLÓGICOS: ATITUDES DE ESTUDIANTES ARGENTINOS UNIVERSITÁRIOS DE INGLÊS COM NÍVEL INTERMEDIÁRIO
}

\begin{abstract}
Resumo. O presente estudo faz parte da tese de doutorado intitulada "Efeitos de áudio e vídeos curtos autênticos: reconhecimento de processos fonológicos e atitudes de estudantes argentinos universitários de inglês com nível intermédio". Este trabalho, em particular, enfoca às atitudes dos estudantes relacionadas com áudios e vídeos curtos autênticos para o reconhecimento de processos fonológicos do inglês falado. Os sujeitos do estudo são estudantes da cadeira de Fonética e Fonologia Inglesa I das graduações de Professor e Tradutor Público de Inglês, na Faculdade de Línguas (FADEL) da Universidade Nacional de Comahue (UNCo), Argentina. Se utilizou um desenho quase experimental baseado em dois grupos: o audiovisual e o áudio. $\mathrm{O}$ primeiro $(\mathrm{n}=32)$ assistiu à segmentos de vídeos autênticos para desenvolver a percepção de processos fonoaudiológicos, enquanto que o segundo $(n=34)$ foi instruído mediante o mesmo material, mas sem o suporte visual. Os segmentos utilizados foram: vídeo musical, pré-estreia, propagandas comerciais, documentários, curto metragem e cena de filme. As atitudes dos estudantes se mediram antes e depois dos procedimentos descritos. Para este fim, se aplicaram um questionário informativo e outro de valoração. Através da análise dos dados se deduz que os estudantes manifestam uma atitude positiva ante ambos recursos, sendo mais positiva ante ao audiovisual, tanto antes como depois do experimento. Se espera seguir explorando os efeitos dos diferentes tipos de vídeos breves na percepção de processos fonológicos e em outros aspectos da pronunciação.
\end{abstract}

Palavras-chave: vídeos curtos autênticos, áudios, atitudes, processos fonoaudiológicos, ensino.

\section{Introducción}

En el quehacer cotidiano, quienes tienen la tarea de enseñar aspectos de la fonética y la fonología a futuros docentes y traductores de inglés se enfrentan con problemáticas de diversa índole. Para ser más precisos, es habitual que los estudiantes afronten dificultades en la producción de sonidos, patrones rítmicos o entonación, como también es usual que el alumnado enfrente obstáculos en la percepción y entendimiento del habla corrida. Este fenómeno, en el que se concatenan los sonidos para agilizar el proceso comunicativo y ganar tiempo y energía, está constituido por diferentes procesos fonológicos que alteran el discurso oral o hablado. Por ejemplo, en una sucesión de palabras se puede advertir la omisión e inserción de sonidos para suavizar la transición entre ellas o su modificación debido a la influencia que ejercen otros sonidos adyacentes (Celce-Murcia, Brinton \& Goodwin, 2010). Lo cierto es que todos los hablantes, sin importar su lengua materna, toman atajos en el discurso oral, ocasionando problemas en los discentes de idiomas, quienes esperan reconocer palabras que conocen y no aquellas que han cambiado su forma (Grant, 2014). Es así que, inevitablemente, los estudiantes argentinos de inglés desconocen palabras que conocen.

Una posible solución al problema descrito consistiría en ayudar a los aprendices a percibir los procesos fonológicos del habla corrida, ya que su reconocimiento facilitaría 
el entendimiento de distintos registros del idioma inglés (formal - informal) de sus principales variedades (Británica - Americana). En virtud de ello, durante mucho tiempo los estudiantes han sido expuestos a muestras del habla corrida mediante audios reales. También progresivamente, con el avance tecnológico, la iniciación de la era digital y el apogeo de Internet, el alumnado del aula de pronunciación ha descifrado ejemplos del lenguaje fluido que se encuentran en videos auténticos breves. En reiteradas ocasiones se han empleado uno u otro recurso, únicamente porque la intuición, las creencias o experiencias guían estas decisiones, o porque se han observado y descrito sus características. Ahora bien, ¿qué actitudes poseen los estudiantes hacia estos recursos a la hora de percibir estas modificaciones del habla? Esta precisamente es la pregunta que impulsa el presente trabajo.

\section{Definición de habla corrida y procesos fonológicos}

El término habla corrida es "usado en lingüística para referirse al lenguaje hablado analizado de manera continua" (Crystal, 2008, p. 101). Desde una perspectiva integradora, se puede afirmar entonces que el habla corrida está conformada por diversos aspectos tales como acentuación de palabras o frases, formas fuertes y débiles, ritmo y procesos fonológicos. El proceso de acentuación a nivel de frase y el ritmo ejercen una gran influencia en la pronunciación de sonidos del habla conexa y viceversa. De hecho, la función principal de los procesos del habla corrida es la de mantener la regularidad del patrón rítmico del inglés mediante la compresión de las sílabas que se encuentran entre las sílabas acentuadas (Clark \& Yallop, 1995, citado por Alameen, 2014).

Ahora bien, desde la perspectiva de la comunicación, el habla corrida no consiste en producir cada sonido de forma aislada y con la máxima claridad; más bien presenta una concatenación de fonemas que modifican o alteran el idioma hablado para comunicar un mensaje con máxima eficacia (Dalton \& Seidlhofer, 1994). En otras palabras, al minimizar los esfuerzos articulatorios para lograr que el mensaje sea entendido, los hablantes realizan ajustes en el habla corrida tomando características fonéticas de sonidos adyacentes. Estos fenómenos que implican eliminar, insertar o cambiar sonidos son denominados procesos del habla corrida (Alameen \& Levis, 2015) o procesos fonológicos (Yoshida, 2016) y ocurren dentro de una palabra o en palabras contiguas. De su uso recurrente proviene la existencia de diferentes tipos de procesos fonológicos que no ocurren libremente en el lenguaje espontáneo, sino bajo ciertas condiciones (Roach, 2009; Joyce, 2014) o reglas fonológicas. Los distintos tipos de procesos fonológicos que en líneas generales describe la literatura son:

- Elisión: una consonante o vocal es omitida, como por ejemplo en "I told him" /aI təold him/ /ai təold Im/

- Enlace: conexión de sonidos, como sucede en "sonner or later" /'su:nər o: 'leitə/

- Asimilación: cambio en sonidos adyacentes para que haya una mayor similitud entre ellos, como por ejemplo en "have to" /hæv tə//hæf tə/

- Coalescencia: en una secuencia de sonidos, el primer sonido y el segundo crean un tercer sonido con características fonéticas de los sonidos originales, como ocurre en "don't you /dəont ju/ /dəontfu/

\section{Videos cortos auténticos: Definición, clasificación, ventajas y desventajas}

Diferentes investigadores (Brown \& Hilferty, 1986; Cahill, 2006; Rogerson, 2006; Rahimi \& Chalak, 2017; Underwood \& Wallace, 2012; Wong, et al., 2017) consideran el material auténtico como una valiosa herramienta en la instrucción de procesos fonológicos. Para ellos, la concienciación de los ajustes del habla corrida se incrementa gracias a la exposición a este tipo de material. De un modo similar, en el área 
de la enseñanza de una lengua extranjera, distintos autores (Arcario, 1992; Bahrani \& Sim, 2012; Kaiser, 2011; King, 2002; MacWilliam, 1986; Stempleski, 2002; Stempleski \& Tomalin, 2001 y Walker, 1999) enfatizan la importancia de utilizar segmentos de video. Pero, ¿qué se entiende por videos cortos auténticos? Según las definiciones señaladas por Taylor (2009) y Snelson \& Perkins (2009), estos son imágenes movibles acompañadas generalmente por sonido que presentan ejemplos de lenguaje real en uso y se caracterizan por tener una corta duración, que se extiende desde segundos hasta 10 minutos.

En la actualidad, debido al avance tecnológico y la accesibilidad que ofrece Internet, una gran variedad de videos cortos auténticos están al alcance tanto de docentes como de estudiantes. Si bien es posible elaborar un listado más exhaustivo, la siguiente tipología encauza y organiza los principios establecidos en este trabajo. Por lo tanto, los videos cortos auténticos se pueden clasificar en:

- $\quad$ Escenas: partes de películas, novelas, comedias o series televisivas.

- Preestrenos: presentan una versión resumida de películas que no han sido estrenadas.

- $\quad$ Cortometrajes: películas cortas que tienen principio, desarrollo y fin. La duración aproximadamente oscila desde unos segundos hasta 15 minutos.

- Documentales: programas acerca de un tema en particular o un grupo de personas que presentan hechos e intentan informar a la audiencia.

- Videos musicales: cortometrajes realizados para la difusión de un tema musical a través del medio televisivo o portales de Internet.

- Avisos comerciales: propagandas en forma de películas cortas o voces que narran las ventajas de un producto.

El fenómeno de videos cortos auténticos ofrece una serie de ventajas. Una de ellas es que su brevedad y la cantidad de lenguaje que estos recursos presentan admiten que puedan ser vistos varias veces en una clase y explorados al máximo (Kaiser, 2011). Su corta duración permite que los estudiantes mantengan su atención e interés, particularidades que suelen perderse cuando se utilizan audiovisuales largos (Snelson \& Perkins, 2009). Lejos de estar constituidos por hechos aislados, los videos breves comprenden situaciones auto-contenidas que presentan un principio, un desarrollo y un final. Esta característica permite utilizarlos como textos audiovisuales independientes que pueden ser explorados en cualquier momento de la clase (Massi \& Blázquez, 2012).

Otra ventaja es que suministran material real contextualizado, en el que se muestran las características propias, tanto prosódicas (velocidad y volumen) como paralingüísticas (gestos, contacto visual y proximidad), del lenguaje espontáneo (Massi \& Blázquez, 2010). Los videos cortos no solo facilitan el desarrollo de distintos aspectos de la pronunciación, sino también el reconocimiento de diversas variedades del idioma inglés (Lowe, 2007). Además, incluyen valores, costumbres y tradiciones que caracterizan a la comunidad en la que los hablantes están inmersos. Esta particularidad impulsa la comunicación intercultural que implica la concientización y tolerancia de la cultura propia y ajena (Sweeting, 2009).

No obstante, y a pesar de las ventajas descritas, este material también presenta una serie de inconvenientes. Como ya se ha expresado anteriormente, los videos se caracterizan por presentar información auditiva y visual de manera simultánea. Al respecto, MacWilliam (1986) sostiene que la información proveniente del canal sonoro podría ser ignorada, debido a la atracción que ejerce la información derivada del canal visual. En esta línea, Wagner (2007) afirma que algunos investigadores sostienen que el uso de material audiovisual podría obstaculizar la comprensión, dado que este puede 
causar que los estudiantes se distraigan. A su vez, afirma que, en muchas oportunidades, los discentes evitan prestar atención a las pistas visuales que ofrece este tipo de material y se centran en completar las tareas asignadas. De hecho, la Teoría de Carga Cognitiva (Sweller, 2005; Mayer, 2014), advierte que demasiada información en uno de estos canales, auditivo o visual, podría entorpecer el entendimiento y, por consiguiente, el aprendizaje. Otra cuestión a considerar es que el empleo de segmentos de video pone en riesgo la riqueza provista por el contexto y la interpretación del mensaje.

\section{Audiovisual auténtico, motivación y procesos fonológicos}

La literatura describe al audiovisual auténtico como entretenido y motivador (Bradley, 2013; Mayer, 2014; Sherman, 2003). Según Field (2008), Gilmore (2007) y Nunan (1999), esta cualidad es atribuida a este tipo de material, debido a que los estudiantes disfrutan al identificar aquellos conocimientos del idioma inglés que fueron adquiridos en el aula en el mundo real. En este sentido, el aprendizaje es significativo cuando el contenido es contextualizado y se conecta con la realidad, por lo que la exposición a la lengua por medio de este recurso es esencial. Esta premisa es corroborada por Peacock (1997), quien lleva a cabo un estudio empírico en el que advierte un incremento de la motivación en estudiantes universitarios coreanos que han sido expuestos a material auténtico. A su vez, es importante destacar que el alumnado que tiene un alto grado de motivación reduce su ansiedad y aprende la lengua eficazmente, según la hipótesis del filtro afectivo propuesta por Krashen (1985). De hecho, la familiaridad con el contenido audiovisual juega un rol importante en dicho proceso. Es decir, los estudiantes están acostumbrados a mirar un programa de televisión o película de manera relajada, por lo que esta reacción puede ser transferida a la clase y contribuir en la reducción del filtro afectivo (Taylor, 2009). Por tanto, el material auténtico permite que los estudiantes experimenten con el lenguaje no sólo de manera cognitiva sino emocional (Yang, 2016; Castillo, Insuasty y Osorio, 2017).

En relación con videos breves, para Walker (1999), los segmentos con una duración máxima de 10 minutos mantienen el interés de los estudiantes. Esta visión es compartida por Derry, Sherin \& Sherin (2014), quienes afirman que la inclusión de sonido y animación en las clases incrementa el entusiasmo y fomenta el trabajo autónomo del alumnado. En esta línea, Massi \& Blázquez (2008) indican que la exposición a diversos géneros a través de videos breves promueve el desarrollo de comportamientos autónomos en los discentes, ya que esta dinámica posibilita su eventual interacción con textos similares fuera del aula.

En cuanto a los procesos fonológicos del habla corrida, la literatura enfatiza la importancia de enseñar dicho fenómeno (Brown, 2014; Carly, Mees \& Collins, 2018). De hecho, distintas investigaciones comprueban la relación entre su instrucción y el desarrollo de la comprensión auditiva (Ahmadian \& Matour, 2014; Demirezen, 2016; Ito, 2014; Ku \& Wong, 2019; Solukhi, 2015). Sin embargo, la marginalidad que ha sufrido este aspecto de la pronunciación debido a la desorientación metodológica que los educadores experimentan es notable (Nokes, 2018; Zarei \& Doostkam, 2014). Diversos autores, Lu \& Kuo (2011), Rogerson (2006) y Sánchez (2017) han estimulado la implementación de material auténtico en la instrucción de procesos fonológicos y han solicitado un análisis más exhaustivo de este tipo de recurso. A este respecto, existe una escasez de estudios, ya que solo algunos investigadores han explorado el uso de canciones (Carreira, 2008 y Ting \& Kuo, 2012) y de películas (Chung, 2008; Rahimi \& Chalak, 2017 y Wang, 2005) en la enseñanza de los ajustes del habla corrida. Ante este panorama, el presente trabajo pretende no solo fomentar la enseñanza de procesos fonológicos, sino aportar una visión más profunda de la autenticidad en la percepción de los ajustes del habla corrida. 
Otro aspecto a tener en cuenta es la lengua materna de los sujetos de estudio. Según la información recabada, hasta el momento, no se han realizado investigaciones que analicen las actitudes hacia los recursos utilizados en la percepción de procesos fonológicos de estudiantes universitarios argentinos cuya lengua materna es español. El presente estudio pretende abrir un camino en esta dirección.

\section{Método}

Hipótesis

La pregunta en la que se basa el desarrollo de este trabajo, y ha sido expuesta al comienzo del mismo, se materializó en la siguiente hipótesis:

- Los estudiantes manifiestan una actitud más positiva hacia el uso de videos cortos auténticos en el reconocimiento de procesos fonológicos del inglés que hacia el uso de audios cortos auténticos.

Para someter a prueba esta hipótesis se implementó un método mixto, constituido tanto por un componente cuantitativo como cualitativo.

\section{Muestra}

La población del presente estudio está compuesta por individuos argentinos que estudian las carreras universitarias de Profesor y Traductor Público de Inglés y que poseen un conocimiento intermedio de inglés y de fonética y fonología. El subgrupo que representó un reflejo fiel de esa población (Hernández Sampieri, Fernández Collado y Baptista Lucio, 2010) se conformó por los estudiantes que cursaban la asignatura Fonética y Fonología Inglesa I, correspondiente al segundo año de las carreras de Profesor y Traductor Público de Inglés de la Facultad de Lenguas (FADEL), en la Universidad Nacional del Comahue (UNCo), Argentina. Un requisito para poder cursar esta asignatura consiste en haber superado la asignatura Introducción a la Lengua Inglesa I, lo cual garantiza un conocimiento intermedio tanto de la lengua inglesa como de fonética y fonología.

Previamente al desarrollo de esta investigación, el alumnado de Fonética y Fonología Inglesa I constituía dos grupos de práctica de aproximadamente 40 estudiantes cada uno. Se conservó en la muestra esta organización natural consistente en dos grupos intactos.

\section{Variables y procedimiento}

Las variables independientes se correspondieron con los métodos asignados a cada grupo: audio y audiovisual. La variable dependiente se definió en términos de la actitud u opinión positiva de los estudiantes hacia el uso de videos cortos auténticos en la percepción de procesos fonológicos del inglés. Para su medición se implementaron dos instrumentos: un cuestionario informativo y un cuestionario de valoración, empleados antes y después de la intervención respectivamente. Este período de instrucción tuvo una duración de 6 semanas, en las que el grupo audiovisual $(n=32)$ fue expuesto a videos cortos auténticos, mientras que el grupo audio $(n=34)$ fue expuesto al mismo material sin su componente visual. En cuanto al material audiovisual, este se seleccionó cuidadosamente, es decir, se trató de encontrar un alto grado de paralelismo entre los distintos fragmentos de video elegidos en términos de uso de estructuras gramaticales y léxicas propias de un nivel de inglés intermedio, diversos tipos de procesos fonológicos y la variedad General British (GB), debido a la preponderancia otorgada a este acento en los años iniciales de estas carreras de grado. 
En ambos grupos se utilizaron las mismas guías didácticas basadas en un video musical, un preestreno, avisos comerciales, un documental, un cortometraje y una escena de película. Estas se elaboraron en función del enfoque basado en estrategias de aprendizaje (Mendelsohn, 1994) y mantuvieron una estructura semejante. Es decir, las guías didácticas se diseñaron teniendo en cuenta las tres fases de aprendizaje propuestas por Stempleski (2002), antes de escuchar/ver, mientras se escucha/ve y después de escuchar/ver. Las actividades propuestas se crearon con precisión, para evitar una excesiva carga cognitiva. Estas tenían no sólo la finalidad de desarrollar la percepción de procesos fonológicos, sino la de crear un ambiente educativo activo en el que abundaran procedimientos autónomos gestores de pensamiento reflexivo.

\section{Instrumentos y análisis de los datos}

El primer instrumento, el cuestionario informativo, comprendía dos secciones. La sección A contenía un conjunto de preguntas demográficas que permitían recoger información acerca de las siguientes categorías: nombre, edad, género, ciudad natal, lengua materna e idiomas que habla en su hogar. La sección B recogía preguntas abiertas que permitieron a los participantes expresar libremente su opinión o actitud acerca de audios y videos cortos auténticos en el desarrollo de la percepción de los procesos fonológicos y su preferencia por uno u otro recurso. Este tipo de cuestiones permitió encauzar la investigación hacia una etapa de observación de las principales tendencias de respuestas. A partir de estos patrones generales se asignaron categorías creadas para establecer una relación con el tema estudiado. Posteriormente, las frecuencias de cada categoría se interpretaron en términos de porcentajes. A partir de los datos arrojados se realizó una prueba de homogeneidad de factores, a través del estadístico de Pearson Chicuadrado y la correspondiente corrección de Yates. La información recogida a través de este cuestionario fue fundamental, en tanto que permitió no solo un análisis descriptivo inicial, sino su posterior comparación con las respuestas obtenidas a través del otro instrumento de medición.

Una vez finalizada la intervención, se administró el segundo instrumento, el cuestionario de valoración, organizado en función de tres preguntas abiertas destinadas a obtener la opinión de los estudiantes sobre: 1) el tipo de recurso utilizado (audio/audiovisual), 2) el disfrute de las clases impartidas y 3) las preferencias por audio o audiovisual según la experiencia vivida en este estudio. Para su análisis se observaron las principales tendencias de opiniones, se asignaron categorías y se consideró su frecuencia de mención. Con respecto a las preferencias por uno u otro recurso, se empleó un modelo lineal generalizado que permitió analizar y comparar las preferencias de los estudiantes antes y después del tratamiento. El nivel de nivel de significación fijado para la prueba estadística fue de $95 \%(\alpha=0,05)$.

\section{Resultados}

\section{Cuestionario informativo: Caracterización general de los grupos}

Los resultados de la sección A del cuestionario informativo permitieron obtener una descripción general de ambos grupos en términos de género, edad, lengua materna e idioma hablado en el hogar. Con respecto al género, ambos grupos, audio $(n=34)$ y audiovisual $(n=32)$, estaban constituidos mayoritariamente por mujeres, contando con un $76 \%$ de estas en el grupo audio y un $73 \%$ en el grupo audiovisual. El porcentaje restante estaba conformado por hombres.

Las edades oscilaron entre 18 y 45 para el grupo audio y entre 18 y 38 años para el grupo audiovisual. La mayoría de los estudiantes de los grupos audio (61\%) y audiovisual (62\%) vivían en General Roca, ciudad en la que se encuentra la Facultad de Lenguas. El estudiantado restante viajaba diariamente hasta el asentamiento universitario 
desde ciudades aledañas. La lengua materna de la totalidad de los sujetos era español. Un número reducido de estudiantes manifestó que en su casa hacían uso de otras lenguas, como inglés ( $\mathrm{n}=5$ grupo audio y $\mathrm{n}=3$ grupo audiovisual) y francés ( $\mathrm{n}=1$ grupo audio).

Los resultados del análisis de los datos provenientes de la sección B del cuestionario informativo, opiniones sobre audios y videos, se dan a conocer a continuación. En cuanto a los resultados de preferencia por uno u otro recurso, su análisis se efectuará comparativamente con los resultados obtenidos a partir del cuestionario de valoración.

\section{Opiniones sobre audios antes de la intervención}

Las opiniones que manifestaron los estudiantes de ambos grupos sobre el uso de audios se centraron en cuatro categorías: muy útil, útil, necesario y difícil de entender. Los valores obtenidos en términos de porcentajes se muestran en la Figura 1. Como se puede apreciar, el material de audio fue estimado como útil por la mayoría de los estudiantes, en un 35\% en el grupo audio y un $44 \%$ en el grupo audiovisual. La segunda categoría más mencionada fue muy útil. Al respecto, el $29 \%$ de los discentes del grupo audio eligió este calificativo, mientras que esta misma selección se observó en un 22\% en el grupo audiovisual. Otra categoría que emergió de los datos recogidos fue la de considerar al material de audio necesario. Este adjetivo fue utilizado por el $24 \%$ del alumnado del grupo audio y el $22 \%$ del grupo audiovisual. Asimismo, el $12 \%$ de los estudiantes de ambos grupos optaron por la categoría negativa difícil de entender.

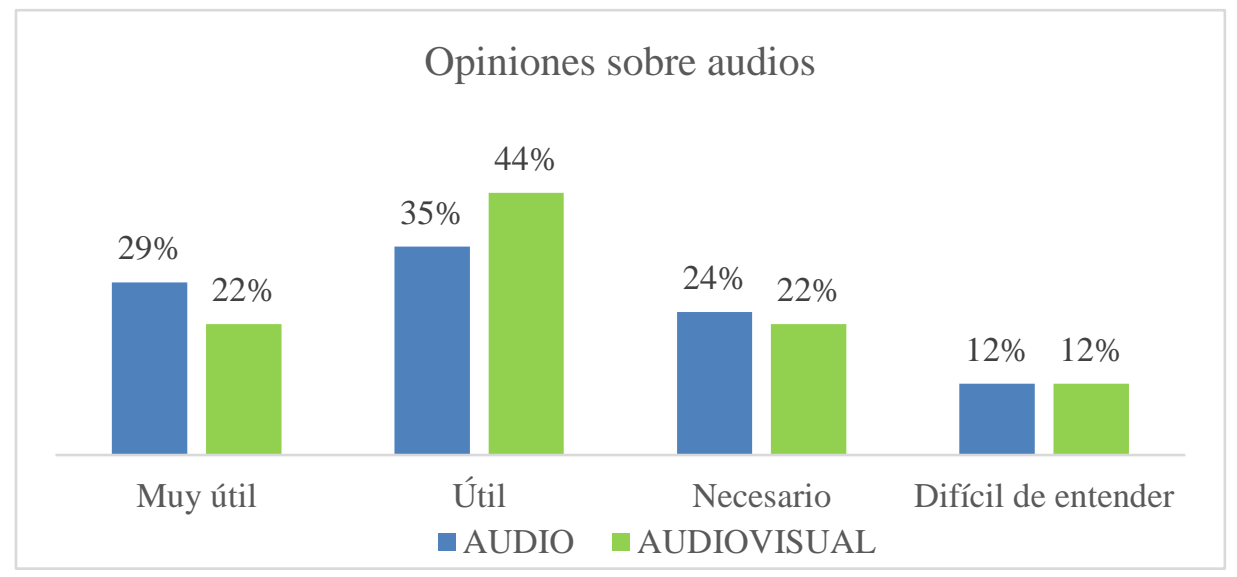

Figura 1. Opiniones sobre el uso de audios en ambos grupos. Fuente: Elaboración propia.

\section{Opiniones sobre videos antes de la intervención}

Las opiniones sobre el uso de videos se focalizaron en cinco categorías: entretenido, motivador, muy útil, útil y distrae. Los porcentajes obtenidos se pueden visualizar en la Figura 2. Si se observa la representación gráfica con atención, se advierte que el material audiovisual fue estimado como muy útil por un $26 \%$ de los integrantes del grupo audio y un $44 \%$ de los participantes del grupo audiovisual, posicionando a este calificativo como el más frecuente en ambos grupos. La segunda categoría más mencionada fue entretenido. Al respecto, el $21 \%$ del grupo audio eligió este término, mientras que el 34\% del grupo audiovisual le atribuyó esta cualidad. Otra categoría que emergió de los datos recogidos fue la de considerar útil al material audiovisual. Este adjetivo fue utilizado por el $24 \%$ del alumnado del grupo audio y el $13 \%$ del grupo audiovisual. Asimismo, el $24 \%$ de los estudiantes del grupo audio afirmaron que el material audiovisual es motivador, frente al 9\% del grupo audiovisual. Únicamente el 5\% de los discentes del grupo audio optó por la categoría de opinión negativa distrae. 


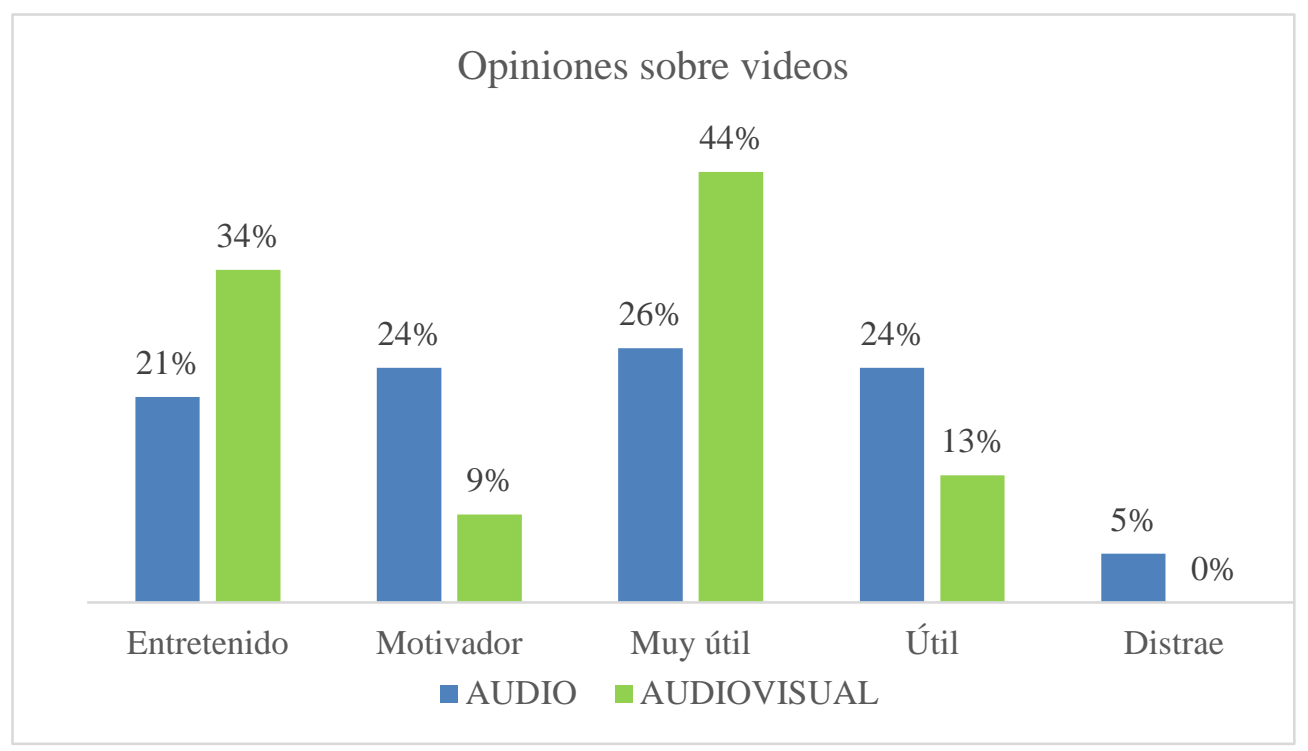

Figura 2. Opiniones sobre el uso de videos en ambos grupos. Fuente: Elaboración propia.

De la totalidad de las variables consideradas se comprobó la homogeneidad inicial de los grupos mediante la prueba estadística de Pearson Chi-cuadrado, la correspondiente corrección de Yates y la prueba de comparación de medias.

A continuación se muestran los resultados derivados de las tres preguntas abiertas que conforman el cuestionario de valoración.

\section{Resultados del cuestionario de valoración}

La primera pregunta abierta de este instrumento de valoración permitió a los estudiantes expresar su punto de vista sobre el recurso empleado. De este modo, los integrantes del grupo audio manifestaron su opinión sobre la utilización de audios, mientras que los participantes del grupo audiovisual compartieron su visión sobre el uso de videos.

Los resultados obtenidos respecto de las opiniones de los integrantes del grupo audio se pueden observar en la Figura 3. Al respecto, el 51\% de la totalidad de los estudiantes del grupo audio manifestó que el material de audio evita la distracción y aumenta el nivel de atención y concentración en los procesos fonológicos. Por su parte, un 34\% expresó que entender el contenido de este tipo de recurso implica un gran esfuerzo de procesamiento, pero que, a la larga, esta limitación se ve compensada por un desarrollo de la habilidad auditiva.

Otra opinión que surgió hace referencia a la posibilidad que brinda este recurso de hacer las actividades al mismo tiempo que se escucha. Dicho parecer fue manifestado por el $9 \%$ de los integrantes del grupo audio. Y solamente el $6 \%$ restante consideró que prescindir del componente visual hace las clases más aburridas. 


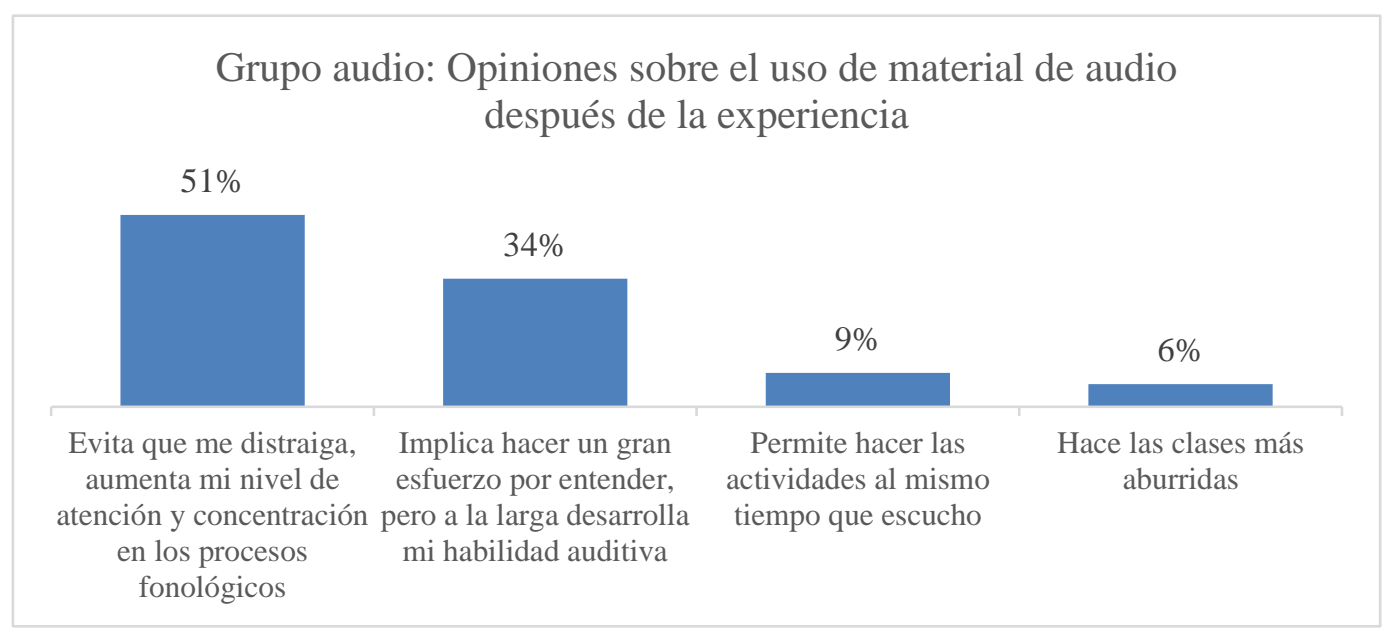

Figura 3. Opiniones del grupo audio sobre el uso de audios después de la experiencia. Fuente: Elaboración propia

Los resultados derivados de las opiniones del alumnado del grupo audiovisual sobre el uso de videos después de la experiencia están representados en la Figura 4. Al respecto, el $43 \%$ manifestó que este material permite entender el contexto, lo cual facilita la identificación de los procesos fonológicos. Por otra parte, el 16\% expresó que ver videos aumenta su interés en el tema en cuestión. Otra opinión que surgió, y en un mismo porcentaje, $16 \%$, muestra que la visualización de los movimientos de los labios de los hablantes ayuda a reconocer estos ajustes del habla corrida. Asimismo, un porcentaje idéntico, $16 \%$, percibió que existe una conexión entre la presencia del componente visual y la disminución del nivel de atención en los procesos fonológicos. El 9\% restante consideró que ver videos hace las clases más entretenidas.

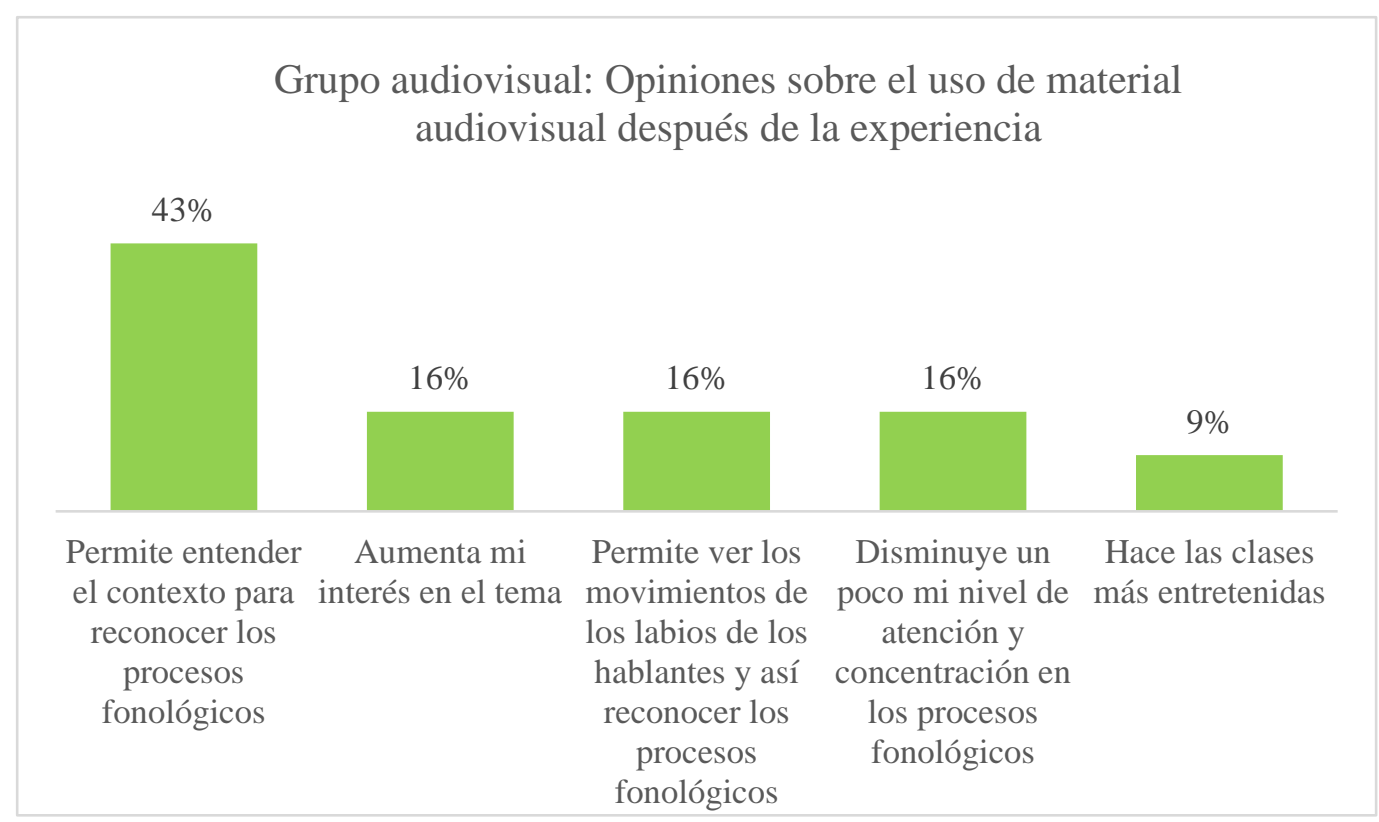

Figura 4. Opiniones del grupo audiovisual sobre el uso de videos después de la experiencia. Fuente: Elaboración propia.

Otra de las preguntas incluidas en el cuestionario de valoración hacía referencia a la dicotomía entre haber disfrutado las clases impartidas por medio del recurso 
audio/audiovisual para identificar procesos fonológicos o no. A su vez, esta pregunta invitaba a los estudiantes a reflexionar acerca de los motivos de dicha respuesta.

Con respecto al disfrute de la experiencia, el 94\% de los discentes del grupo audio aseguraron haber disfrutado las clases a través de este recurso. El 6\% restante del grupo audio manifestó no haber disfrutado. El motivo de la respuesta fue atribuido a que escuchar sin ver hacía las clases un poco más aburridas. Contrariamente, en el grupo audiovisual, la totalidad de los estudiantes (100\%) dio una respuesta afirmativa. Los motivos se pueden visualizar en la Figura 5. Uno de los motivos más notorios que propició el disfrute del aprendizaje de procesos fonológicos fue que las clases eran dinámicas y entretenidas, ya que el $27 \%$ y el $28 \%$ de los estudiantes de los grupos audio y audiovisual, respectivamente, expresó esta opinión. De todos modos, para los estudiantes del grupo audiovisual, la razón más relevante $(31 \%)$ se basó en el hecho de que el material seleccionado era divertido. No obstante, este motivo únicamente fue manifestado por el 9\% de los estudiantes del grupo audio. Los integrantes de ambos grupos destacaron la importancia de utilizar material auténtico, debido a que les resultó motivador ver/escuchar a hablantes nativos de la lengua meta. Este motivo fue expresado por el $24 \%$ de los estudiantes del grupo audio y el 16\% del grupo audiovisual. A su vez, el $21 \%$ de los participantes del grupo audio y el $13 \%$ del grupo audiovisual manifestaron que las clases impulsaron el reconocimiento de procesos fonológicos de manera progresiva. El 12\% del alumnado del grupo audio y el $9 \%$ en el grupo audiovisual estimó que escuchar/ver audios/videos cortos y variados resultó un desafío. Únicamente en el grupo audio, en un $6 \%$, surgió una categoría que afirma que escuchar sin ver dio lugar a usar la imaginación. Solo en el grupo audiovisual, el 3\% de los estudiantes aseguró que su disfrute se debió a que estas habían sido de ayuda para recordar las reglas que subyacen los procesos fonológicos.

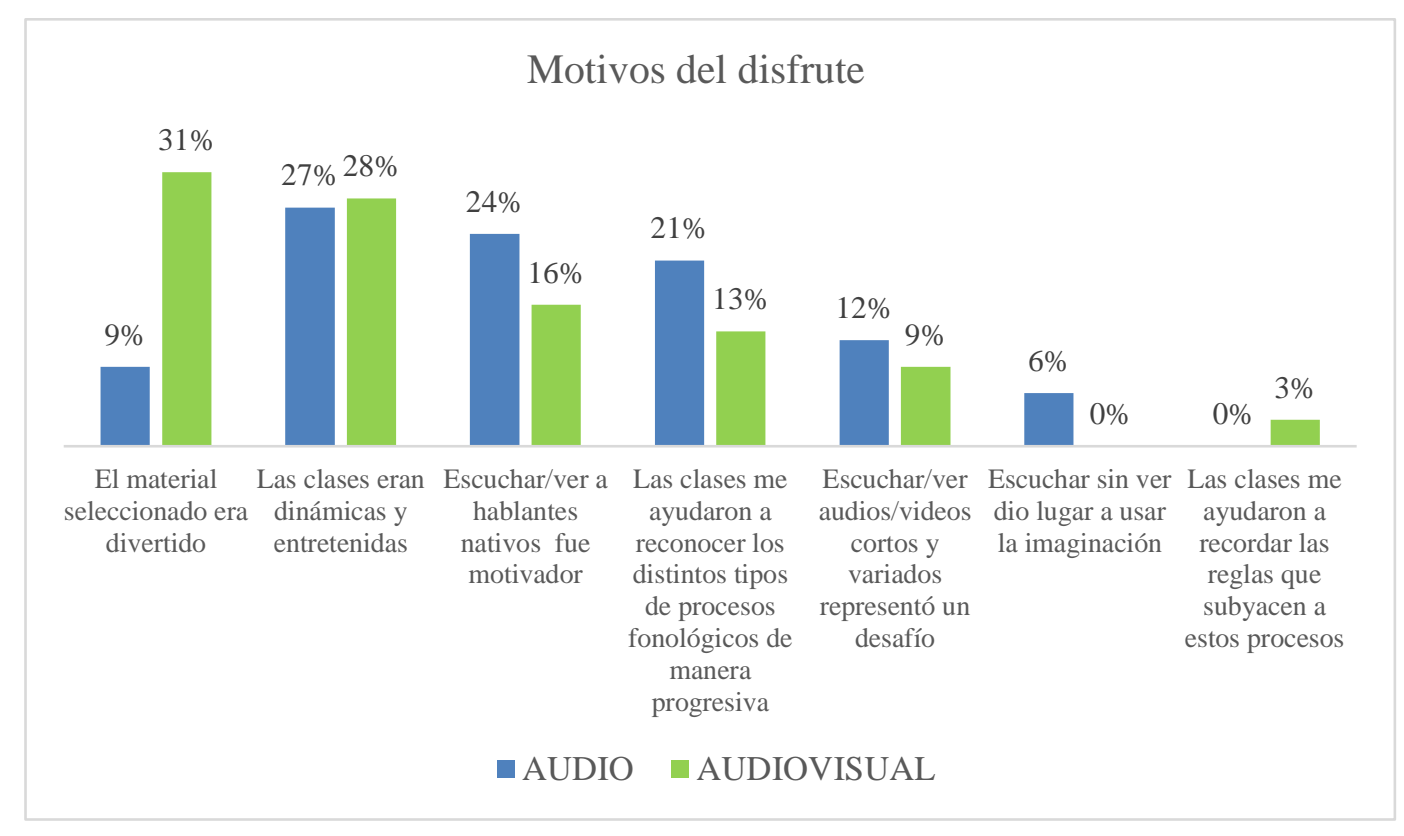

Figura 5. Motivos del disfrute. Fuente: Elaboración propia.

La última pregunta abierta que se incluyó en el cuestionario de valoración hacía referencia a la preferencia de los alumnos por el uso de audios o videos cortos auténticos en la identificación de los ajustes del habla corrida. Como ya hemos puntualizado, esta cuestión también fue incluida en el cuestionario informativo, por lo que los datos recolectados son analizados comparativamente. 
La Tabla 1 muestra los tres efectos principales y sus correspondientes interacciones dobles. Según los resultados estadísticos, solo existen diferencias significativas en las preferencias de los participantes, ya que el valor de probabilidad alcanzado $(\mathrm{p}=0,0405)$, es inferior al nivel de significación establecido $(0,05)$.

Tabla 1

Pruebas de hipótesis marginales para los efectos fijos.

\begin{tabular}{lcccc}
\hline SOURCE & numDF & denDF & F-value & p-value \\
\hline Grupo & 1 & 1 & 3,37 & 0,2078 \\
Momento & 1 & 2 & 0,01 & 0,9227 \\
Prefiere & 1 & 2 & 23,69 & 0,0405 \\
Grupo: Momento & 1 & 2 & $1,6 \mathrm{E}-03$ & 0,9716 \\
Momento: & 2 & 2 & 0,05 & 0,9480 \\
Prefiere & & & & \\
Grupo: Prefiere & 2 & 2 & 2,83 & 0,2610 \\
\hline
\end{tabular}

Nota: Elaboración propia.

Como se puede apreciar en la Tabla 2, los valores de la media indican una preferencia significativamente mayor por el recurso audiovisual $(M=21,63)$, que por el recurso audio $(\mathrm{M}=8,76)$ o ambos $(\mathrm{M}=2,00)$. Estos resultados revelan un favoritismo marcado y una opinión positiva del alumnado hacia los materiales en formato video.

Tabla 2

Medias y errores estándares para prefiere.

\begin{tabular}{clllllll}
\hline PREFIERE & PredLin $^{\mathrm{a}}$ & E.E. & Media & E.E. & & & \\
\hline AUDIOVISUAL & 3,07 & 0,11 & 21,63 & 2,33 & A $^{*}$ & & \\
AUDIOS & 2,17 & 0,17 & 8,76 & 1,50 & & B & \\
AMBOS & 0,69 & 0,40 & 2,00 & 0,79 & & C \\
\hline
\end{tabular}

Nota: Elaboración propia.

a. PredLin se refiere a predictor lineal.

b. E.E. Se refiere a error estándar.

*Medias con una letra común no son significativamente diferentes $(p>0,05)$.

En síntesis, del análisis de los resultados surge la existencia de diferencias significativas en las preferencias de los participantes a favor del recurso audiovisual. Las preferencias por uno u otro recurso se mantuvieron estables y no variaron a causa de la influencia del tipo de intervención o del momento de medición. Sin embargo, los motivos de favoritismo sí lo hicieron según el análisis manual de las principales tendencias de opiniones. Por ejemplo, las razones por las cuales un grupo de participantes prefirieron audios variaron sustancialmente antes y después del tratamiento. 
Como se puede observar en la Figura 6, antes del tratamiento el 65\% de los estudiantes expresó que escuchar sin ver agudiza el oído y mejora la percepción de procesos fonológicos. Esta opinión se redujo al 21\% después del tratamiento. Antes de la intervención, el 35\% del alumnado opinaba que escuchar sin ver evitaba la distracción y aumentaba el nivel de atención y concentración en los procesos fonológicos. Esta opinión aumentó al 79\% después del tratamiento.

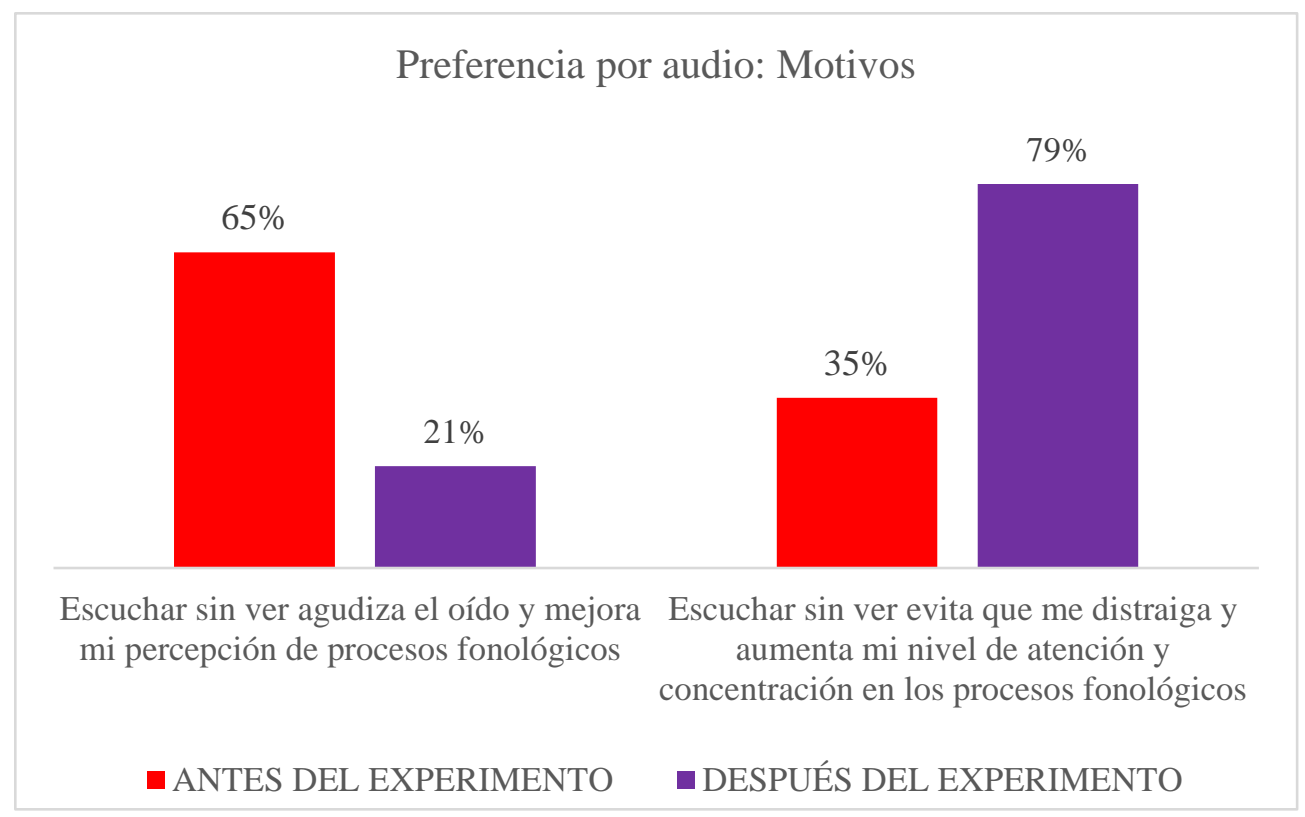

Figura 6. Motivos de preferencia por audios antes y después de la intervención. Fuente: Elaboración propia.

Respecto a la preferencia por videos, la Figura 7 muestra como antes de la intervención las opiniones de los alumnos estaban distribuidas en cuatro categorías con porcentajes semejantes. Al respecto, el $30 \%$ consideró que escuchar y ver ayuda a entender el contexto y a identificar procesos fonológicos, mientras que el $25 \%$ de los participantes expresó que aprendían visualmente. Coincidentemente, otro $25 \%$ de los participantes manifestó que ver videos es entretenido y motivador. En un porcentaje menor $(20 \%)$, los estudiantes indicaron que escuchar y ver el movimiento de los labios ayuda en entender lo que se dice y a identificar los procesos fonológicos.

Los motivos de predilección por el material audiovisual variaron después de la intervención. Por ejemplo, en la Figura 7 se observa que dos categorías, aprendo visualmente y ver el movimiento de los labios ayuda a identificar procesos fonológicos, disminuyeron sustancialmente, de un $25 \%$ al $14 \%$ y de un $20 \%$ a un $7 \%$, respectivamente. Contrariamente, escuchar y ver ayuda a entender el contexto y a identificar procesos fonológicos y ver videos es entretenido y motivador aumentaron, de un $30 \%$ a un $33 \%$ y de un $25 \%$ a un $37 \%$, respectivamente. Esta última se convirtió en la razón manifestada por la mayoría. Otro resultado que invita a la reflexión es el surgimiento de la nueva categoría los efectos de sonido son tan atractivos que aumentan mi curiosidad por ver los videos. 


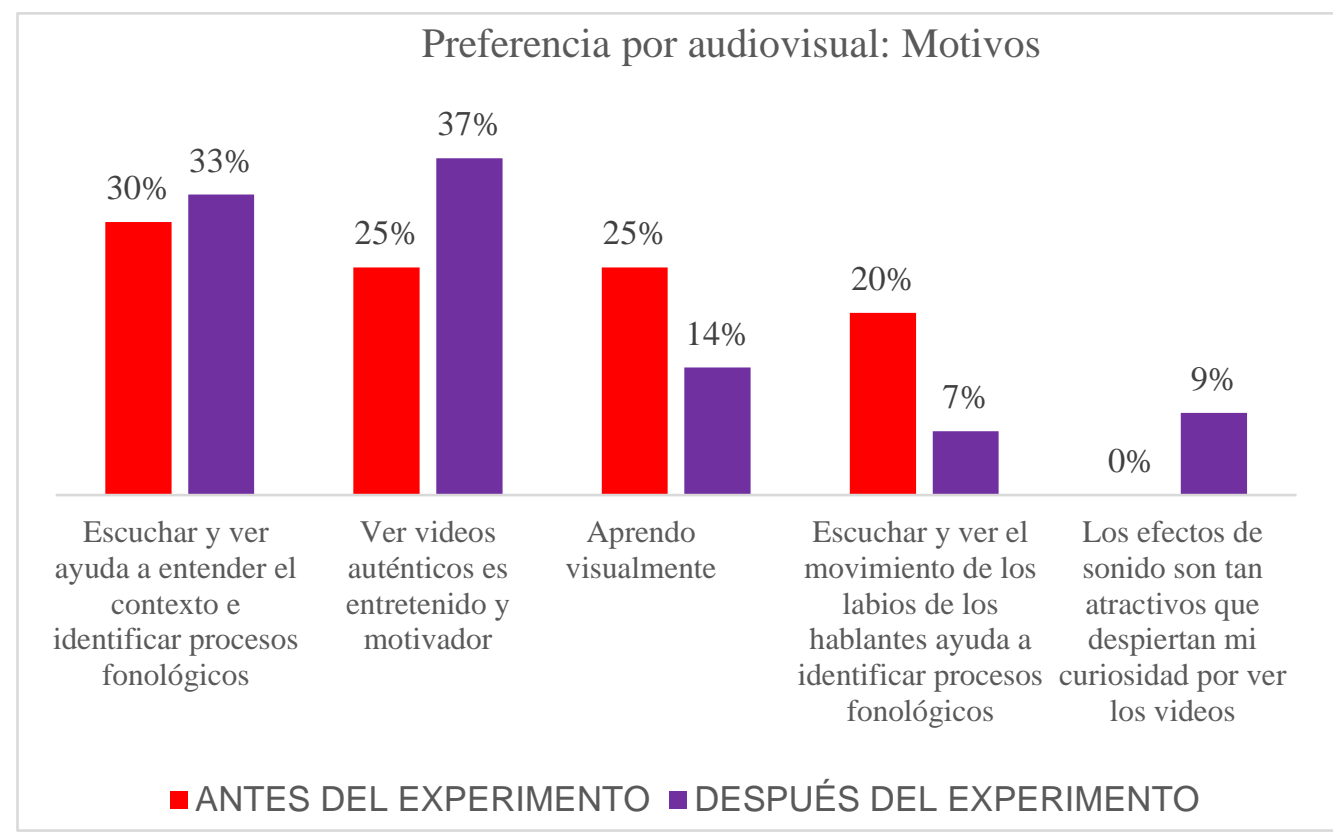

Figura 7. Motivos de preferencia por videos antes y después de la intervención. Fuente: Elaboración propia.

\section{Discusión y conclusiones}

A partir de los resultados obtenidos se comprueba la hipótesis sometida a prueba en este trabajo de investigación, que sostiene que los estudiantes manifiestan una actitud y opinión más positiva hacia el uso de videos cortos auténticos en el reconocimiento de procesos fonológicos del inglés que hacia el uso de audios cortos auténticos.

Para desarrollar plenamente los argumentos a favor de la comprobación de esta hipótesis es importante repasar las opiniones recogidas antes de la intervención. Según los resultados del cuestionario informativo, la mayoría de los estudiantes de ambos grupos manifestaron una valoración positiva sobre el uso de audios y videos. Las opiniones negativas, aunque en un porcentaje reducido, se centraron en la preocupación por el detrimento de la concentración a causa de las imágenes presentes en el material audiovisual y la dificultad en el entendimiento que puede provocar el material de audio. Mayoritariamente, los integrantes de ambos grupos valoraron el material de audio como útil y necesario, mientras que estimaron al material audiovisual como muy útil, entretenido y motivador. De lo expuesto se dedujo una atracción mayor por el material audiovisual, aunque no se descartó que tanto los estudiantes del grupo audio como los participantes del grupo audiovisual experimentaron una sensación optimista hacia ambos recursos antes de la intervención. Esta actitud positiva parecería indicar un alto nivel de motivación inicial.

Las opiniones expresadas a partir del cuestionario de valoración permiten respaldar la comprobación de esta hipótesis. Con respecto al disfrute de las clases abocadas al aprendizaje de procesos fonológicos, la totalidad de los discentes del grupo audiovisual afirmaron haber experimentado un sentimiento de goce, principalmente conducido por la diversión y entretenimiento que caracterizó al material seleccionado. Por su parte, una proporción mínima del grupo audio afirmó haberse aburrido debido a la ausencia del componente visual. De forma general, se observó una alta demarcación del terreno emocional fijada por la mayoría del estudiantado al expresar que el dinamismo y entretenimiento de las clases cumplieron un rol central en el proceso de aprendizaje de procesos fonológicos. De todo lo expuesto se deduce que el material auténtico fomentó la creación de una atmósfera relajada en el desarrollo de las clases. A su vez, este ambiente 
libre de tensiones impulsó a los estudiantes a sentirse cómodos y a reducir su filtro afectivo, como bien señala Krashen (1985) en su Hipótesis de Filtro Afectivo.

En cuanto a la preferencia del alumnado por audios o videos cortos auténticos, los participantes expresaron su preferencia por estos últimos, no solo antes, sino también después del tratamiento. Estos resultados son coincidentes con los hallados por Alameen (2014). En su estudio, los estudiantes valoraron positivamente los dos recursos utilizados, audio y representaciones gráficas de ondas sonoras (audiovisual), pero manifestaron una actitud más positiva hacia el recurso audiovisual.

Por otra parte, en el presente estudio, un análisis de las motivaciones de preferencia permitió advertir que estos variaron después de la experiencia de aprendizaje. El motivo que prevaleció en aquellos que optaron por los audios fue que la ausencia de imágenes incrementó la atención en los procesos fonológicos, opinión predominante en los resultados de las opiniones del grupo audio respecto del recurso audio. En este sentido, la visión de los discentes concuerda con MacWilliam (1986) y Wagner (2007), quienes sostienen que el componente visual puede causar distracción en el alumnado. Además, este pensamiento estaría en concordancia con Mayer (2014), quien considera que la ausencia de imágenes evitaría la sobrecarga de los canales de procesamiento, tanto auditivo como visual, y favorecería la atención al fenómeno estudiado.

En aquellos que optaron por los videos, el motivo que predominó y ascendió notablemente después de la intervención fue que ver videos auténticos es entretenido y motivador. De hecho, la literatura lo describe de igual forma (Field, 2008; Nunan, 1999, Gilmore, 2007; Sherman, 2003; Bradley, 2013; Mayer, 2014), debido a que este recurso posibilita establecer una conexión entre el mundo del aula y el real. La lectura de estos resultados permite afirmar que existe una tendencia creciente de un sector del estudiantado hacia la vinculación entre material audiovisual auténtico y motivación. Estos hallazgos son coincidentes con los obtenidos en estudios anteriores tales como los de Rahimi \& Chalak (2017), Peacock (1997), Underwood \& Wallace (2012) y Wang (2005). Otro de los motivos de preferencia hace referencia a que este recurso les permitió entender el contexto necesario para reconocer procesos fonológicos. Dicha percepción fue manifestada por más de la mitad de los estudiantes del grupo audiovisual cuando expresaron su opinión hacia el recurso audiovisual. Esta apreciación es coincidente con la de Wong, et al., (2017), quienes afirman que el conocimiento acerca del contexto de la situación ayuda a entender lo que se está diciendo y predecir las palabras a utilizar.

Una opinión que contribuye en la relevancia de la duración del recurso es la que señala que escuchar/ver audios/videos breves y variados representó un desafío. La importancia atribuida a la duración del recurso por parte del estudiantado va en línea con los planteamientos de Arcario (1992), Kaiser (2011), King (2002), Lowe (2007), MacWilliam (1986), Stempleski \& Tomalin (2001) y Walker (1999), quienes enfatizan que los segmentos de video deberían ocupar un rol más central en la enseñanza de lenguas extranjeras. Sin embargo, el presente trabajo no ha examinado su potencial en profundidad. Resultaría interesante explorar qué tipos de videos breves, ya sean videos musicales, preestrenos, avisos comerciales, documentales o escenas, favorecen la percepción de los ajustes del habla corrida y en qué medida.

De todo lo expuesto se deduce que los audios cortos auténticos son valorados positivamente, aunque en menor medida. En este caso, la actitud positiva de los alumnos parecería estar asociada con la atención en la forma, específicamente con la efectividad del recurso a la hora de identificar los procesos fonológicos. La instrucción basada en videos cortos auténticos está vinculada con la diversión, la cual ayuda a los estudiantes a disminuir su filtro afectivo y a aumentar su motivación (Taylor, 2009).

Las limitaciones encontradas en este estudio se relacionan con el número de participantes. Inicialmente se contó con dos grupos intactos conformados por 39 y 40 
estudiantes que se redujeron a 34 y 32 respectivamente. Esto se debió, probablemente, a que la intervención se llevó a cabo cerca de la finalización del curso académico, período en el que los estudiantes deben cumplir con un alto nivel de obligaciones. Creemos que una muestra conformada por la totalidad de los participantes podría haber otorgado mayor sustento a la generalización de los resultados de este estudio a otras poblaciones que reúnen las mismas características.

Según la información recabada, ningún estudio se ha focalizado en alumnos universitarios de las titulaciones de Profesor y Traductor Público de Inglés. Por consiguiente, la presente investigación puede considerarse pionera en este sentido. Con respecto a la lengua materna de los sujetos, la mayoría de los estudios llevados a cabo hasta el momento involucran participantes asiáticos. Si bien Alameen (2014) ha incluido un portugués, un árabe y un español, además de sujetos asiáticos, los resultados alcanzados hasta el momento no son concluyentes en relación a estas lenguas. Este estudio realiza un aporte en esta dirección mediante el análisis de la perspectiva de estudiantes cuya lengua materna es español.

Otro de los aportes de este estudio radica en que la visión del alumnado conduce a revitalizar la práctica docente en términos del momento en el que cada recurso podría utilizarse. Por ejemplo, una clase organizada en función de las tres fases de aprendizaje, antes, durante y después de ver o escuchar (Mendelsohn, 1994; Stempleski, 2002) podría comenzar con la exposición a material auténtico de audio, un único canal, es decir sin imágenes, y podría finalizar con la presentación del video correspondiente. De este modo, aumentaría no solo la atención, mediante la información provista por el canal auditivo, sino la incertidumbre, generada por la ausencia de imágenes. Paralelamente, para saciar esta curiosidad, los estudiantes desarrollarían otras capacidades. Al final de la clase, lograrían darle sentido a lo que se escucha a través de la exposición a la información por medio de ambos canales, lo cual generaría un ambiente libre de tensiones. Considerando que el recurso audiovisual acrecienta la motivación y que los audios cortos auténticos aumentan la atención en los procesos fonológicos, una alternativa eficiente, entonces, consistiría en combinar estos recursos en distintos momentos de una misma clase.

Este estudio examina el material auténtico en la instrucción de procesos fonológicos, según lo solicitado por Lu \& Kuo (2011) y Rogerson (2006) y ofrece evidencia sobre la relación entre el recurso audiovisual y el disfrute. Dicho hallazgo permite, en consonancia con lo requerido por Wong, et al., (2017), Nokes (2018) y Zarei \& Doostkam (2014), apartar a los docentes de una desorientación metodológica. En definitiva, una de las premisas centrales que constituyen este estudio radica, precisamente, en dar cuenta del potencial del material auténtico y estimular a los docentes a implementarlo de manera adecuada para garantizar los procesos de enseñanza y aprendizaje de los ajustes del habla corrida y de otros aspectos de una lengua extranjera.

\section{Referencias}

Ahmadian, M. \& Matour, R. (2014). The effect of explicit instruction of connected speech features on Iranian EFL learners' listening comprehension skill. International Journal of Applied Linguistics and English Literature, 3(2), 227-236. doi: https://doi.org/10.7575/aiac.ijalel.v.3n.2p.227.

Alameen, G. (2014). The effectiveness of linking instruction on NNS speech perception and production. Disertación doctoral sin publicar. Iowa State University, Ames, USA.

Alameen, G. \& Levis, J. M. (2015). Connected speech. En M. Reed \& J. M. Levis, (Eds.), The handbook of English pronunciation (pp. 159-174). Malden, MA: John Wiley \& Sons. 
Arcario, P. (1992). Criteria for selecting video materials. En S. Stempleski \& P. Arcario (Eds.), Video in second language teaching: Using, selecting, and producing video for the classroom (pp. 109-121). Alexandria, USA: TESOL Publications.

Bahrani, T. \& Sim, T. S. (2012). Audiovisual news, cartoons, and films as sources of authentic language input and language proficiency enhancement. Turkish Online Journal of Educational Technology-TOJET, 11(4), 56-64. Recuperado de http://www.tojet.net/articles/v11i4/1145.pdf.

Bradley, M. (2013). Teaching with film. Vienna, Austria: Stone River Books.

Brown, A. (2014). Pronunciation and phonetics: A practical guide for English language teachers. Abingdon, UK: Routledge.

Brown, J. D. \& Hilferty, A. (1986). The effectiveness of teaching reduced forms of listening comprehension. RELC Journal, 17(2), 59-70. doi: https://doi.org/10.1177/003368828601700204.

Cahill, J. D. (2006). Teaching reduced interrogative forms to low level EFL students in Japan. En J. D. Brown \& K. Kondo-Brown (Eds.), Perspectives on teaching connected speech to second language speakers (pp. 99-125). Honolulu, Hawaii: University of Hawai'i Press.

Carley, P., Mees, I. M. \& Collins, B. (2018). English phonetics and pronunciation practice. Abingdon, UK: Routledge.

Carreira, J. M. (2008). Effects of teaching reduced forms in a university preparatory course. En K. Bradford-Watts, T. Muller \& M. S. Swanson (Eds.), JALT2007 Conference Proceedings (pp. 200-207). Tokyo, Japan: JALT Tokyo.

Castillo Losada, C. A., Insuasty, E. A. y Osorio, J. (2017). The Impact of authentic materials and tasks on students' communicative competence at a Colombian language school. Profile Issues in Teachers' Professional Development, 19(1), 89-104. doi: https://doi.org/10.15446/profile.v19n1.56763.

Celce-Murcia, M., Brinton, D. M. \& Goodwin, J. M. (2010). Teaching pronunciation: A course book and reference guide. New York, USA: Cambridge University Press.

Chung, C. I. (2008). Development of a film-based reduced forms learning system for assisting English listening comprehension. Tesis de maestría sin publicar. National Central University, Jhongli, Taiwan.

Crystal, D. (2008). A dictionary of linguistics and phonetics (6 ${ }^{\mathrm{a}}$. ed.). Oxford, UK: Blackwell Publishing.

Dalton, C. \& Seidlhofer, B. (1994). Pronunciation. Oxford, UK: Oxford University Press. Demirezen, M. (2016). Assimilation as a co-articulation producer in words and pronunciation problems for Turkish English teachers. Educational Sciences: Theory and Practice, 16(2), 477-509. doi: https://doi.org/10.12738/estp.2016.2.0235.

Derry, S. J., Sherin, M. G. \& Sherin, B. L. (2014). Multimedia learning with video. En R. E. Mayer (Ed.), The Cambridge Handbook of Multimedia Learning (2a. ed., pp. 785-812). New York, USA: Cambridge University Press.

Field, J. (2008). Listening in the language classroom. Cambridge, UK: Cambridge University Press.

Gilmore, A. (2007). Authentic materials and authenticity in foreign language learning. Language teaching, 40(2), 97-118. doi: https://doi.org/10.1017/S0261444807004144.

Grant, L. (2014). Pronunciation myths: Applying second language research to classroom teaching. Michigan, USA: University of Michigan Press.

Hernández Sampieri, R., Fernández Collado, C. y Baptista Lucio, P. (2010). Metodología de la investigación ( $5^{\mathrm{a}}$. ed.). DF, México: McGraw Hill. 
Ito, Y. (2014). Japanese learners' listening to English connected speech. Studies in Linguistics \& Language Teaching. 25, 57-72. Recuperado de http://id.nii.ac.jp/1092/00001184/.

Joyce, P. (2014). The development and validation of a second language listening reduced forms test. Iranian Journal of Language Teaching Research, 4(2), 155-174. Recuperado de https://www.semanticscholar.org/.

Kaiser, M. (2011). New approaches to exploiting film in the foreign language classroom. L2 Journal, 3(2), 232-249. doi: https://doi.org/ 10.5070/L23210005.

King, J. (2002). Using DVD feature films in the EFL classroom. Computer Assisted Language Learning, 15(5), 509-523. doi: https://doi.org/10.1076/call.15.5.509.13468.

Krashen, S. D. (1985). The input hypothesis: Issues and implications. Harlow, UK: Longman.

Ku, W. Y. \& Wong, S. W. L. (2019). Effect of shadowing with reduced forms on ESL listening comprehension. Psychological Society Annual Conference, The Education University of Hong Kong, Hong Kong, China.

Lowe, M. (2007). Films in English language teaching. International House Journal, 23, 16-19. Recuperado de http://ihjournal.com.

Lu, Y. H. \& Kuo, F. L. (2011). A survey of EFL teachers' perspectives on connected speech instruction. En Y. N. Leung (Ed.), Selected Papers from the 2011 PAC. The 20th International Symposium on English Teaching (pp. 206-215). Taipei, Taiwan: Crane.

MacWilliam, I. (1986). Video and language comprehension. ELT journal, 40(2), 131135. doi: https://doi.org/10.1093/elt/40.2.131

Massi, M. P. \& Blázquez, B. (2008). Exploiting DVDs' extra features: An added bonus in the EFL class. Humanising Language Teaching (HLT). Free Online EFL Magazine for Teachers, 10(4). Recuperado de http://old.hltmag.co.uk/aug08/mart03.htm.

Massi, M. P. \& Blázquez, B. (2010). The shorter the better: Using shorts in ELT. Modern English Teacher, 19(2), 36-42.

Massi, M. P. \& Blázquez, B. A. (2012). A short is worth a thousand films! Teaching English with Technology (TEwT). Free Online Journal for TESOL Teachers, 12(3), 62-86. Recuperado de: https://www.tewtjournal.org/issues/past-issue2012/past-issue-2012-issue-3/.

Mayer, R. E. (2014). Introduction to multimedia learning. En R. E. Mayer (Ed.), The Cambridge handbook of multimedia learning (2. ${ }^{a}$ ed., pp. 1-26). New York, USA: Cambridge University Press.

Mendelsohn, D. (1994). Learning to listen: A strategy-based approach for the secondlanguage learner. San Diego, USA: Dominie Press.

Nokes, J. (2018). Whaddya call that again? Materials for teaching connected speech. Second Language Studies, 36(2), 27-153. Recuperado de http://www.hawaii.edu/sls/wp-content/uploads/2018/07/Nokes.pdf.

Nunan, D. (1999). Second language teaching \& learning. Boston, USA: Heinle \& Heinle.

Peacock, M. (1997). The effect of authentic materials on the motivation of EFL learners. ELT Journal, 51(2), 144-156.

Rahimi, M. \& Chalak, A. (2017). The effect of connected speech teaching on listening comprehension of Iranian EFL learners. Journal of Applied Linguistics and Language Research, 4(8), 280-291. Recuperado de https://www.semanticscholar.org/.

Roach, P. (2009). English phonetics and phonology: A practical course (4. ${ }^{\mathrm{a}}$ ed.). Cambridge, UK: Cambridge University Press. 
Rogerson, M. (2006). Don'cha know? A survey of ESL teachers' perspectives on reduced form instruction. En J. D. Brown \& K. Kondo-Brown (Eds.), Perspectives on teaching connected speech to second language speakers. Honolulu, Hawaii: University of Hawai'i Press.

Sanchez, D. (2017). Teaching reduced forms: A curriculum guide for Junior High English language teachers using digital technology based activities and classroom games. Propuesta de tesis. University of San Francisco, San Francisco, USA. Recuperado de

https://repository.usfca.edu/cgi/viewcontent.cgi?article=1726\&context=capstone

Sherman, J. (2003). Using authentic video in the language classroom. Cambridge, UK: Cambridge University Press.

Snelson, C. \& Perkins, R. A. (2009). From silent film to YouTubeTM: Tracing the historical roots of motion picture technologies in education. Journal of Visual Literacy, 28(1), 1-27. doi: https://doi.org/10.1080/23796529.2009.11674657.

Solukhi, M. (2015). The effectiveness of reduced forms teaching on students' listening ability in identifying connected speech. Disertación de maestría. IAIN Syekh Nurjati Cirebon University, Ciberon, Indonesia.

Stempleski, S. (2002). Video in the ELT classroom: The role of the teacher. En J. C. Richards \& W. A. Renandya, (Eds.), Methodology in language teaching: An anthology of current practice (pp. 354-367). Cambridge, UK: Cambridge University Press.

Stempleski, S. \& Tomalin, B. (2001). Film. Oxford, UK: Oxford University Press.

Sweeting, A. (2009). Language through film. Sydney, Australia: Phoenix Education Pty. Sweller, J. (2005). Implications of cognitive load theory for multimedia learning. En R. E. Mayer (Ed.), The Cambridge handbook of multimedia learning (1. a ed., pp. 1931). New York, USA: Cambridge University Press.

Taylor, S. (2009). Using Video: Theory. IH Journal, 26. Recuperado de http://ihjournal.com/using-video-theory

Ting, W. Y. \& Kuo, F. L. (2012). Messages behind the unheard sounds: Crossing the word boundaries through songs. NCUE Journal of Humanities, 5, 75-92.

Recuperado http://ir.ncue.edu.tw/ir/bitstream/987654321/14472/1/2040000510006.pdf.

Underwood, P. \& Wallace, M. (2012). The effects of instruction in reduced forms on the performance of low-proficiency EFL university students. The Asian EFL Journal, 14(4), 1-24. Recuperado de https://www.researchgate.net/publication/286007702.

Wagner, E. (2007). Are they watching? Test-taker viewing behavior during an L2 video listening test. Language Learning and Technology, 11(1), 67-86. doi: http://dx.doi.org/10125/44089.

Walker, C. (1999). Teacher's guide to using film and TV. London, UK: Penguin Longman.

Wang, Y. T. (2005). An exploration of the effects of reduced forms instruction on EFL college students' listening comprehension. Tesis de maestría sin publicar. National Tsing Hua University, Hsinchu, Taiwan.

Wong, S., Mok, P., Kien-Hoa Chung, K., Leung, V., Bishop, D. \& Chow, B. (2017). Perception of native English reduced forms in Chinese learners: Its role in listening comprehension and its phonological correlates. TESOL Quarterly, 51(1), 7-31. doi: https://doi.org/10.1002/tesq.273

Yang, L. (2016). Optimizing pronunciation and prosody teaching in second language learning. Conferencia impartida en International Symposium on Applied 
Phonetics, Nagoya, Japan. Recuperado de https://www.researchgate.net/publication/315770663.

Yoshida, M. T. (2016). Beyond repeat after me: Teaching pronunciation to English learners. Alexandria, USA: TESOL Press.

Zarei, R. \& Doostkam, M. (2014). Iranian EFL learners' familiarity with reduced forms in spoken English based on their proficiency level. International Journal of Applied Linguistics and English Literature, 3(6), 68-79. doi: https://dx.doi.org/10.7575/aiac.ijalel.v.3n.6p.68.

Fecha de recepción: 31/05/2020

Fecha de revisión: 01/06/2020

Fecha de aceptación: 22/06/2020 